\title{
TECNOLOGIAS DIGITAIS E DEFICIÊNCIA VISUAL: A CONTRIBUIÇÃO \\ DAS TIC PARA A PRÁTICA PEDAGÓGICA NO CONTEXTO DA LEI \\ BRASILEIRA DE INCLUSÃO
}

\author{
DIGITAL TECHNOLOGIES AND VISUAL IMPAIRMENT: THE \\ CONTRIBUTION OF ICT TO PEDAGOGICAL PRACTICES IN THE \\ CONTEXT OF THE BRAZILIAN LAW FOR THE INCLUSION OF PERSONS \\ WITH DISABILITY
}

\author{
Maria Helena Silveira Bonilla ${ }^{1}$ \\ Manoela Cristina Correia Carvalho da Silva ${ }^{2}$ \\ Taiane Abreu Machado ${ }^{3}$
}

\begin{abstract}
Resumo: Com a promulgação da Lei Brasileira de Inclusão (LBI), confirma-se o direito das pessoas com deficiência à educação em escolas comuns. As Tecnologias da Informação e Comunicação (TIC) podem ser grandes aliadas nesse processo, inclusive para pessoas com deficiência visual, o maior contingente de pessoas entre aquelas que têm deficiências no Brasil e um público para o qual o uso não criterioso de tecnologias digitais pode apresentar sérias barreiras devido à carga imagética associada às TIC. O presente estudo, além de discutir as principais barreiras na comunicação e na informação enfrentadas por pessoas com deficiência visual, apresenta alternativas de como educadores podem incorporar as TIC a sua prática pedagógica e fomentar a colaboração, a descentralização do conhecimento, a autonomia e a criatividade.
\end{abstract}

Palavras-chave: Deficiência visual; TIC; Lei brasileira de inclusão.

\begin{abstract}
With the enactment of the Brazilian law for the inclusion of persons with disability, the right of people with special needs to be educated in regular schools has been confirmed. Information and communication technologies (ICT) can be of great use in this process, even for visually impaired people, the largest contingent of people among those with disabilities in Brazil and an audience for whom the nonjudicious use of digital technologies may present serious barriers due to the imaging load associated to ICT. In the present study, besides discussing the main barriers in information and communication faced by blind people, the authors present alternatives to educators who wish to incorporate ICT into their pedagogical practices and foster collaboration, helping enhance the decentralization of knowledge, autonomy and creativity.
\end{abstract}

Keywords: Visual impairment; ICT; Brazilian law for the inclusion of persons with disability.

\footnotetext{
${ }^{1}$ Doutora em Educação pela Universidade Federal da Bahia (UFBA). Docente associada da Faculdade de Educação da Universidade Federal da Bahia (UFBA), Salvador, Bahia, Brasil. E-mail: bonillabr@gmail.com

${ }^{2}$ Doutoranda em Educação pela Universidade Federal da Bahia (UFBA). Docente adjunta da Universidade Federal da Bahia (UFBA), Salvador, Bahia, Brasil. E-mail: penteacher2@yahoo.com.br

${ }^{3}$ Mestra em Educação pela Universidade Federal da Bahia (UFBA), Salvador, Bahia, Brasil. E-mail: abreu.tam@gmail.com
} 


\section{Introdução}

Já há algumas décadas, o movimento pelos direitos das pessoas com deficiência vem inspirando políticas públicas no Brasil. No entanto, foi somente em 2015 que o país foi contemplado com uma lei cujo foco específico é a inclusão em todas as suas instâncias. A Lei Brasileira de Inclusão (LBI), também conhecida como o Estatuto da Pessoa com Deficiência (Lei no 13.146/2015), foi firmada em 6 de Julho de 2015 e entrou em vigor em 2 de janeiro de 2016.

No âmbito da inclusão escolar, a LBI reafirma o direito das pessoas com deficiência a ter acesso à escola comum. Entretanto, como se é de esperar, a LBI não restringe seu campo de atuação à educação. Além desse tópico, estão incluídas seções que tratam desde o direito à habilitação e à reabilitação até o direito à cultura, ao esporte, ao turismo e ao lazer. É bastante interessante notar também, no atual contexto de avanço na utilização das Tecnologias de Informação e Comunicação (TIC) ${ }^{4}$, o fato de que a LBI não tenha deixado de abordar o assunto e traga seções dedicadas à questão da tecnologia assistiva, da acessibilidade e do direito à informação e à comunicação.

A presença desses tópicos no texto da legislação aponta para a relevância das TIC na rotina das pessoas com deficiência, bem como atesta sua utilidade para aqueles que desejem empreender projetos de inclusão no contexto escolar. As TIC podem introduzir naturalmente as temáticas da deficiência, da acessibilidade e dos direitos humanos em sala de aula; potencializar a interação entre os educandos; e garantir a efetiva participação de uma parcela do alunado historicamente marginalizada: os estudantes com deficiência visual.

Contudo, é preciso sensibilidade e comprometimento profissional. No caso daqueles que trabalham com estudantes com deficiência visual, é preciso lembrar que o advento de novas tecnologias (a fotografia, o cinema, a televisão, o vídeo, as mídias digitais, dentre outros) resultou numa crescente utilização de imagens. Hoje, grande parte dos textos (escritos ou falados) são acompanhados por algum tipo de ilustração (gráficos, tabelas, gravuras, vídeos, dentre outros) ou são transmitidos unicamente pelo canal visual. No entanto, para alunos cegos ou com baixa visão, essas imagens podem constituir uma barreira ao pleno entendimento das mensagens veiculadas. Além disso, mesmo que parte

\footnotetext{
4 As TIC são aqui entendidas como todos os recursos tecnológicos utilizados para mediar processos informacionais e comunicações como, por exemplo, o computador, os softwares, a internet, os jogos eletrônicos, os celulares, dentre outros.
} 
das informações seja transmitida na forma de textos verbais, se esses forem apenas projetados ou exibidos em telas, continuarão inacessíveis a esse público. Portanto, para que a inclusão desses indivíduos seja real, é preciso que eles tenham seus direitos garantidos, não apenas em forma de lei, mas principalmente no estar e fazer cotidiano da sociedade (PILETTI, 2014).

No Brasil, muito ainda precisa ser feito para que os direitos conquistados através da LBI "saiam do papel" e sejam efetivados no cotidiano da escola. As tecnologias digitais podem contribuir muito nesse sentido quando utilizadas por profissionais sensíveis a essas questões. Assim, os objetivos do presente artigo são introduzir o leitor ao texto da LBI, analisar as dificuldades de acesso à informação enfrentadas por pessoas com deficiência visual no ambiente escolar e apresentar alternativas de como os educadores que se utilizam das TIC em sua prática pedagógica podem contribuir para vencer essas dificuldades, auxiliando a participação mais efetiva desses alunos em atividades que envolvam o uso do computador e que tenham a presença de imagens.

\section{Muito prazer, LBI}

Como a perspectiva inclusiva advoga que os sujeitos da legislação (pessoas com deficiência, transtornos globais de desenvolvimento e com altas habilidades/superdotação) devem frequentar classes comuns, todos os professores, não apenas aqueles que trabalham com o Atendimento Educacional Especializado (AEE), são responsáveis por assegurar a boa adaptação e o aproveitamento escolar desses indivíduos. Toda a equipe escolar, portanto, deve unir esforços nesse sentido, buscando, inclusive, familiarizar-se com o texto da LBI.

De acordo com a lei, os sistemas educacionais precisam “[...] garantir condições de acesso, permanência, participação e aprendizagem, por meio da oferta de serviços e de recursos de acessibilidade que eliminem as barreiras e promovam a inclusão plena" (BRASIL, Lei $\mathrm{n}^{\mathrm{o}}$ 13.146, 2015, art. 28), ou seja, deve-se utilizar “[...] serviços e adaptações razoáveis, para atender às características dos estudantes com deficiência e garantir o seu pleno acesso ao currículo em condições de igualdade, promovendo a conquista e o exercício de sua autonomia" (BRASIL, Lei n 13.146, 2015, art. 28).

Portanto, ao elaborar seu plano de curso, é preciso que o docente que pretenda utilizar-se ou solicitar de seus estudantes o uso de apresentações em slides e vídeos, o acesso à internet, a criação de blogs, dentre outros, tenha divisado como irá propor 
dinâmicas e atividades que garantam a plena participação de todos os alunos sem qualquer exceção. Se assim não o fizer, será criada o que a lei denomina de uma "barreira nas comunicações e na informação", ou seja, um "entrave, obstáculo, atitude ou comportamento que dificulte ou impossibilite a expressão ou o recebimento de mensagens e de informações por intermédio de sistemas de comunicação e de tecnologia da informação" (BRASIL, Lei n 13.146, 2015, art. 3).

Desse modo, conforme o artigo 4 da LBI, o docente incorrerá em falta, pois estará, mesmo que não intencionalmente, discriminando a pessoa com deficiência:

Considera-se discriminação em razão da deficiência toda forma de distinção, restrição ou exclusão, por ação ou omissão, que tenha o propósito ou o efeito de prejudicar, impedir ou anular o reconhecimento ou o exercício dos direitos e das liberdades fundamentais de pessoa com deficiência, incluindo a recusa de adaptações razoáveis e de fornecimento de tecnologias assistivas (BRASIL, 2015).

Grande parte desse problema, no entanto, não deve ser atribuído aos docentes individualmente, mas é reflexo de falhas do poder público que deveria garantir a "[...] inclusão em conteúdos curriculares, em cursos de nível superior e de educação profissional técnica e tecnológica, de temas relacionados à pessoa com deficiência nos respectivos campos de conhecimento" (BRASIL, Lei 13.146, 2015, art.28), bem como a “[...] adoção de práticas pedagógicas inclusivas pelos programas de formação inicial e continuada de professores e oferta de formação continuada para o atendimento educacional especializado" (BRASIL, Lei 13.146, 2015, art.28). Isto porque, ao se familiarizar com a temática da deficiência e as necessidades específicas desses estudantes, os docentes estarão melhor preparados para adotar práticas que possam garantir a efetiva participação de seus alunos, além de contribuir para seu melhor aproveitamento.

Um dos recursos a serem utilizados nessa empreitada são as TIC. Segundo a própria legislação, deve ser estimulado "[...] o emprego de tecnologias da informação e comunicação como instrumento de superação de limitações funcionais e de barreiras à comunicação, à informação, à educação e ao entretenimento da pessoa com deficiência" (BRASIL, Lei 13.146, 2015, art.78).

Entretanto, para que isso seja possível, aqueles que trabalham com estudantes cegos ou com baixa visão e se utilizam das TIC, precisam, primeiramente, entender o que é a deficiência visual, como esses indivíduos acessam as tecnologias digitais e quais as principais barreiras para esse acesso. 


\section{Deficiência visual e tecnologias}

Em 2010, foram coletados dados para o censo demográfico brasileiro pelo Instituto Brasileiro de Geografia e Estatística - IBGE. Na ocasião, 18,6\% da população brasileira declarou ter deficiência visual, ou seja, cerca de 35 milhões de pessoas. Neste contingente estão incluídas aquelas com deficiência congênita (desde o nascimento) ou adquirida (devido a acidentes ou a doenças como glaucoma, diabetes, catarata, etc.); bem como aquelas com cegueira ou baixa visão.

A visão é o resultado da interação de diversas funções: acuidade visual ${ }^{5}$, campo visual $^{6}$, coordenação binocular, sensibilidade ao contraste, adaptação à luminosidade, adaptação à obscuridade e visão de cores (LEME, 2003). A combinação dessas funções nos garante a habilidade de percepção de tonalidade, tamanho, distância, formato, disposição ou movimento em um campo de cerca de $180^{\circ}$.

Algumas instituições escolares utilizam a Escala Optométrica de Snellen - para encaminhar aos especialistas os estudantes que apresentam algumas limitações visuais. Sendo assim, duas escalas oftalmológicas, a acuidade visual e o campo visual, são usadas para determinar se um indivíduo é cego ou tem baixa visão:

A Organização Mundial da Saúde (OMS) definiu cegueira como a acuidade visual menor do que 3/60 no melhor olho, com a melhor correção óptica, além de definir a incapacidade visual acentuada (baixa visão) como a acuidade menor do que 6/60 (ou 20/20) no melhor olho, com a melhor correção óptica (TEMPORINI; KARA-JOSÉ, 2004 apud MOSQUERA, 2010, p. 46).

É importante frisar que a distinção entre cegueira e baixa visão se baseia mais em critérios funcionais que em critérios médicos. São considerados indivíduos com baixa visão aqueles que, podendo inclusive ser considerados legalmente cegos, são capazes de utilizar o resíduo visual que possuem para executar tarefas do dia a dia, especialmente as de caráter escolar. Isso quer dizer que, mesmo que o resíduo visual de um indivíduo esteja dentro dos parâmetros clínicos de baixa visão, se ele não for capaz de utilizá-lo e necessitar de instrução em braille, será considerado cego (LEME, 2003).

Qualquer que seja seu grau, sua causa ou o momento de seu aparecimento, o importante é perceber que a deficiência visual não é um problema per si e que esses

\footnotetext{
5 Acuidade visual é a capacidade de distinguir formas. É aferida pela apresentação de caracteres (símbolos, letras ou números) progressivamente menores a uma distância padrão de 20 pés (seis metros) (MOSQUERA, 2010).

${ }^{6}$ Campo visual é a amplitude da área alcançada pela visão, ou seja, a área total que uma pessoa consegue cobrir com os olhos sem que precise mover a cabeça (MOSQUERA, 2010).
} 
indivíduos têm potencial para um desenvolvimento considerado normal a depender do ambiente físico e social no qual estejam inseridos:

Vygotsky [...] enfatizou que o problema da cegueira é meramente instrumental, e se se proporcionarem ao cego formas alternativas de acesso aos aspectos da cultura inacessíveis a ele devido à ausência de visão, o problema será contornado, como no caso do sistema braille, que permite ao cego o acesso à linguagem escrita (VYGOTSKY, 1997 apud LEME, 2003, p.20).

$\mathrm{O}$ avanço tecnológico tem ajudado bastante nesse sentido. Muitas foram as conquistas em termos de tecnologia assistiva para facilitar o dia a dia dessas pessoas e hoje já existe um verdadeiro arsenal de itens à disposição. Os recursos vão desde os mais tradicionais (óculos bifocais e monofocais, lupas, bengala, reglete ${ }^{7}$, soroba ${ }^{8}$, régua para escrita cursiva ${ }^{9}$, máquina Perkins para escrita em braille, dentre outros.) até os mais avançados (calculadoras e relógios que falam, bengalas com sensor laser, etiquetas com gravação de áudio ${ }^{10}$, identificador de notas de dinheiro e de cores, dentre outros).

$\mathrm{O}$ advento do computador e da internet deu ainda maior impulso às inovações. Para estarem conectados e poderem usufruir do universo digital, pessoas com deficiência visual contam com: teclados com letra ampliada e contraste, software para ajuste de cores e tamanho das informações (efeito lupa), software leitores de tela, softwares de reconhecimento de voz, softwares leitores de texto impresso (OCR $)^{11}$, software para impressão aumentada, impressora braille, impressão em relevo, linha braille ${ }^{12}$, dentre outros.

No caso dos celulares, os aparelhos de última geração, já dispõem de recursos de acessibilidade, como por exemplo: leitores de tela integrados ao sistema, o que dá a cegos e pessoas com baixa visão acesso a todas as funções do aparelho (mesmo aqueles com tecnologia touch screen) e a uma gama de aplicativos, como o Global Positioning System (GPS) para cegos, o aplicativo que faz o celular vibrar quando alguém sorri, ou aquele que reconhece imagens, fazendo uma busca na internet para identificar o objeto fotografado ou filmado pelo aparelho.

\footnotetext{
${ }^{7}$ Recurso criado para a escrita braille. Assemelha-se a uma régua vazada e é sempre utilizada com um outro instrumento pontudo chamado "punção".

${ }^{8}$ Instrumento de cálculo matemático (adição, subtração, multiplicação, etc.) adaptado para o uso de pessoas com deficiência visual.

${ }^{9}$ Réguas vazadas para que pessoas com deficiência visual escrevam em aberturas retangulares.

10 Etiquetas para identificação e organização de objetos como CDs, DVDs, medicamentos, roupas, etc. Após serem gravadas, são lidas por um sensor óptico dotado de sintetizador de voz.

${ }^{11}$ O OCR permite converter tipos diferentes de documentos, como papéis escaneados, arquivos em PDF e imagens capturadas com câmera digital em dados pesquisáveis e editáveis. Assim, o documento pode ser lido por sintetizadores de voz.

${ }^{12}$ Teclado que reproduz em braille o texto que está na tela do computador.
} 
Portanto, ao contrário do que alguns poderiam pensar, pessoas com deficiência visual não são avessas à tecnologia. É somente o alto custo dos equipamentos e a escassez de oferta, já que a maioria deles é importada, que impede a sua utilização em larga escala. Para esses sujeitos, a tecnologia é sinônimo de autonomia e o meio através do qual barreiras (tanto arquitetônicas, quanto de mobilidade, nas comunicações e na informação) podem ser vencidas, garantindo acesso à educação, trabalho, cultura e lazer. Cabe, portanto, ao professor tirar proveito da predisposição positiva desse público para com as TIC.

\section{Vencendo barreiras nas comunicações e na informação: a contribuição das TIC}

A comunicação é uma prática imemorial e intrínseca à própria natureza humana sem a qual não haveria “[...] a possibilidade do social, a relação com o outro, o entendimento entre os sujeitos, a transmissão do saber historicamente acumulado, a coordenação das ações, o estabelecimento de normas" (PRETTO; BONILLA, 2014, p. $4)$.

Inicialmente baseada em trocas face a face, a comunicação humana vem, ao longo da história, assumindo novos contornos, sofrendo grande influência dos avanços tecnológicos (sinais de fumaça, correios, telégrafo, rádio, dentre outros). A crescente presença das TIC no cotidiano e a revolução trazida pela web 2.0, por exemplo, contribuíram para a instalação de um novo paradigma no qual a horizontalidade, a interatividade, a mobilidade e a inteligência coletiva são fundamentais.

Essa nova concepção de comunicação permite que indivíduos oriundos das mais diferentes partes do mundo possam estar conectados em rede, trabalhando colaborativamente e realizando trocas simbólicas de naturezas diversas (textos verbais, sons, imagens ou produções híbridas) a partir da comodidade de seus lares, de qualquer outro local ou através de aparelhos que lhes garantam acesso à internet.

A escola, obviamente, não ficou imune a esse processo e pode lucrar muito com essas mudanças. Para Moura (2009, p. 50), “O acesso a conteúdo multimídia deixou de estar limitado a um computador pessoal (PC) e estendeu-se também às tecnologias móveis (celular, Pocket PC, Tablet PC, Notebook), proporcionando um novo paradigma educacional, o mobile learning ou aprendizagem móvel, através de dispositivos móveis".

Os debates em torno do uso das TIC em sala de aula, em todo o país, têm suscitado diferentes opiniões, uma vez que, a sua implantação é enfatizada não apenas como um 
meio de aprimoramento educacional, mas também como um recurso para aqueles sujeitos que necessitam utilizá-los como um suporte para a aprendizagem dos conteúdos escolares.

Portanto, a possibilidade de comunicação horizontalizada permite que os sujeitos aprendentes, alunos e professores [...] possam compartilhar suas ideias, suas culturas, seus referenciais, suas concepções de mundo, aprendendo, todos com todos, e contribuindo para uma compreensão mais ampla, crítica e complexa da própria sociedade. Possibilita ainda que professores e alunos participem e/ou desencadeiem movimentos ativistas em torno de questões sociais e profissionais, interferindo em seu entorno e na sociedade (PRETTO; BONILLA, 2014, p.22).

Para que tudo isso possa ser concretizado, no entanto, é preciso que as TIC não sejam utilizadas meramente como instrumentos de apoio, obedecendo à mesma lógica de transmissão de conhecimentos que, historicamente, domina a escola. É preciso lembrar que o conhecimento não deixou de estar centralizado nos professores ou nos livros para agora passar a ocupar as redes. A lógica digital é outra, pois as TIC devem oportunizar a horizontalidade, garantindo a TODOS a liberdade para não só criar como também: usar, copiar, reproduzir e remixar conteúdo livremente. E os alunos com deficiência visual não podem estar alijados desse processo.

O primeiro passo para uma prática efetiva nesse sentido é conhecer como estudantes com deficiência visual usam o computador e acessam a internet ${ }^{13}$. Em geral, pessoas cegas ou com baixa visão utilizam leitores de tela em conjunto com o teclado. Assim, experiência de videntes e não videntes com o computador é diferente. A audição não é sintética como a visão. Os leitores de tela leem um elemento de cada vez e sempre da esquerda para a direita e de cima para baixo. Além disso, eles não são capazes de ler imagens a não ser que haja uma descrição em texto associada a elas.

Quanto aos sítios da internet, para que eles possam ser acessados é preciso que os mesmos sigam uma série de parâmetros ${ }^{14}$. A LBI, inclusive, determina que "é obrigatória a acessibilidade nos sítios da internet mantidos por empresas com sede ou representação comercial no País ou por órgãos de governo", que "telecentros comunitários que receberem recursos públicos federais para seu custeio ou sua instalação e lan houses devem possuir equipamentos e instalações acessíveis" e que esses mesmos locais “devem garantir, no mínimo, $10 \%$ (dez por cento) de seus computadores com recursos de acessibilidade para pessoa com deficiência visual, sendo assegurado pelo menos 1 (um)

\footnotetext{
${ }^{13}$ Uma visita a Sala de Recursos Multifuncionais (SRM) pode ser bastante instrutiva.

14 A norma WCAG 2.0 contém diretrizes de acessibilidade para conteúdo web e pode ser acessada gratuitamente em vários sítios da internet.
} 
equipamento, quando o resultado percentual for inferior a 1 (um)" (BRASIL, Lei 13.146, 2015 , art. 63, grifo do autor).

Um bom exercício de sensibilização tanto para professores, como para colegas de alunos com deficiência visual é tentar utilizar o computador (ou celular) via leitores de tela e acessar diferentes sítios da internet. Atividades como essa podem, inclusive, ser utilizadas para introduzir a temática da deficiência e dos direitos humanos e suscitar um debate saudável em sala de aula.

Outro exercício bastante útil para esse fim é a exibição de trechos de filmes sem a projeção das imagens, ou seja, apenas com o áudio ligado. Quanto do conteúdo do filme pode ser compreendido pelos alunos desse modo? Essa última atividade é particularmente útil para introduzir um recurso de tecnologia assistiva capaz de lidar com o único tipo de informação que não pode ser acessada através de leitores de tela, ou seja, as imagens. Esse recurso é denominado de Audiodescrição (AD).

A AD torna produtos visuais (fotografias, pinturas, esculturas, ilustrações em livros didáticos, cartazes em sala de aula, apresentações de slides, etc.) ou audiovisuais (filmes, peças de teatro, programas de TV, etc.) acessíveis a pessoas cegas ou com baixa visão. Ela consiste na transformação de imagens em palavras para que informações-chave transmitidas de modo essencialmente visual não passem despercebidas.

O primeiro passo no sentido de tornar conteúdo imagético acessível em sala de aula, portanto, é tentar selecionar produtos com AD. Atualmente, já é possível encontrar filmes em DVD e na internet com o recurso, bem como parte da programação das redes de televisões abertas é audiodescrita. No entanto, como a oferta de materiais com AD ainda está longe de ser ideal, é preciso também instrumentalizar os próprios professores para que eles mesmos possam audiodescrever ao vivo os materiais que utilizam.

Alguns profissionais do AEE possuem cursos introdutórios em AD e podem auxiliar os professores da classe comum. Se esse não for o caso, é possível encontrar cursos presenciais ou a distância voltada para os docentes. O investimento em formação nesse sentido, irá beneficiar não só os estudantes com deficiência visual, pois, apesar do público primário da $\mathrm{AD}$ ser composto por pessoas cegas ou com baixa visão, pesquisas têm apontado que o recurso também pode beneficiar pessoas com deficiência intelectual, autistas, disléxicos e idosos.

Um professor sensível à questão da diversidade pode, inclusive, dar um passo além. Por que não delegar parte das descrições aos estudantes videntes? Se o professor ensinasse aos seus alunos os princípios básicos da $\mathrm{AD}$, as relações em sala de aula teriam 
muito a ganhar, pois, dessa forma, os próprios alunos poderiam auxiliar seus colegas. Uma experiência exitosa nesse sentido ocorreu na Universidade de Granada na Espanha:

Nesse caso, um aluno do curso de Fisioterapia teve suporte em aulas que versavam sobre patologias isquêmicas arteriais. Voluntários sentavam-se ao seu lado e descreviam em sussurros não só as ilustrações presentes em slides e transparências, mas também a linguagem corporal do docente, os elementos visuais da interação dos demais alunos com o professor, e até mesmo as reações emocionais dos outros alunos diante de imagens que consideravam repulsivas. Desse modo, o aluno cego pôde não só acompanhar o conteúdo da aula, como também entender melhor o que acontecia ao seu redor (LINARES, 2008 apud SILVA, 2012, p. 295).

Experiências como essa são inspiradoras e revelam o quanto a colaboração é importante. Como exposto anteriormente, o trabalho colaborativo, conjuntamente com a horizontalidade, a interatividade e a mobilidade, constitui a base da nova lógica trazida pelas TIC e que deve ser incorporada à prática pedagógica de educadores comprometidos com uma escola em sintonia com o seu tempo e aberta à diversidade.

O uso das novas tecnologias no processo de ensino e aprendizagem, traz consigo aspectos diferenciados. É preciso primeiramente ponderar e definir que tipo de educação se almeja desenvolver e que tipo de estudante se pretende formar (KENSKI, 2007, p.77). Para a autora, entre as distintas discussões necessárias na educação, se faz necessário contextualizar o acesso e uso das TIC nas instituições escolares, pois é fundamental observar os objetivos educacionais e alinhar com a proposta pedagógica da escola. Afinal, a tecnologia também serve para auxiliar e aperfeiçoar o ensino e o aprendizado, tornando as aulas mais interativas e dinâmicas.

É nesse sentido que procuramos contribuir, trazendo três exemplos de como a tecnologia pode ser utilizada nessa nova perspectiva. Como primeira sugestão, trazemos aplicativos gratuitos para smartphone que funcionam conectando pessoas com deficiência visual e videntes em redes de colaboração. Desse modo, quem enxerga, literalmente, "empresta" os olhos a quem não vê. Sempre que uma pessoa cega precisa de auxílio (saber a data de validade de um produto, descobrir a cor de um item de roupa numa loja, achar a lata certa em um armário, dentre outros), uma rede de voluntários é acionada via videochamada. Então, o voluntário que aceita a chamada descreve o que vê. O aplicativo também concede pontos aos usuários por pessoa ajudada, o que funciona como um incentivo.

A utilização de aplicativos como esse pode trazer inúmeros benefícios à comunidade escolar (alunos e professores), com a vantagem de que seu raio de ação supera em muito os muros da escola. Para os cegos, o aplicativo pode ser útil tanto para 
a consecução de tarefas do cotidiano, como para as de caráter escolar. Para os videntes, é uma chance de exercitar a cidadania. Para ambos, uma excelente oportunidade de conhecer pessoas novas e, inclusive, fazer novas amizades. A utilização do recurso favorece, portanto, a colaboração e dá aos usuários autonomia de onde, quando e para que fins utilizar a tecnologia. Além disso, a figura do professor deixa de estar no centro do processo, uma vez que os próprios alunos podem assumir a tarefa de protagonistas, solicitando ou oferecendo ajuda quando quiserem.

A segunda sugestão é a utilização dos podcasts. Trata-se de uma ferramenta gratuita, disponível online e que pode ser utilizada para disponibilizar arquivos de áudio gravados ${ }^{15}$ por tema. Sua utilização pode trazer vários benefícios, tais como: o ritmo de cada aluno é respeitado, uma vez que cada gravação pode ser interrompida e retomada a qualquer momento, bem como repetida várias vezes. E uma vantagem adicional é que os próprios alunos podem produzir os conteúdos na forma de áudios que podem circular na rede (BOTTENTUIT JUNIOR; COUTINHO, 2009).

A utilização de podcasts tem uma dupla função. Em primeiro lugar, beneficia o corpo discente ao criar uma espécie de biblioteca virtual onde podem estar compiladas, por exemplo, aulas, textos de referência para estudo e entrevistas sobre temas relevantes num formato acessível, tanto para videntes como para pessoas com deficiência visual. Em segundo lugar, possibilita aos estudantes o exercício da colaboração e da interatividade, quando, para a consecução dos podcasts, grupos de alunos têm que trabalhar em conjunto, discutir, opinar, editar e aprimorar o trabalho uns dos outros presencialmente ou via ferramentas como redes sociais, listas e fóruns de discussão. Projetos maiores que envolvam toda a comunidade escolar também podem ser elaborados e a criação de uma rádio escolar pode ser uma alternativa interessante, especialmente porque pessoas com deficiência visual têm historicamente uma relação bastante próxima com esse tipo de mídia.

Por fim, a terceira sugestão refere-se ao estudo de diretrizes de acessibilidade e a obrigatoriedade de que toda atividade ou trabalho escolar em grupo tenha que ser acessível, especialmente se apresentado via computador ou postado em rede. Nesse caso,

\footnotetext{
15 Quando arquivos de áudio não são permitidos, tanto o material produzido pelo professor quanto a produção do aluno precisam ser convertidos. No caso do professor, de tinta para braille. No caso do aluno, de braille para tinta. É necessário, portanto, que cada vez mais o corpo docente utilize arquivos em formatos acessíveis. Segundo a LBI, "Consideram-se formatos acessíveis os arquivos digitais que possam ser reconhecidos e acessados por softwares leitores de tela ou outras tecnologias assistivas que vierem a substituí-los, permitindo a leitura com voz sintetizada, ampliação de caracteres, diferentes contrastes e impressão em braille" (BRASIL. Lei 13.146, 2015, art.68).
} 
o professor deve estimular a presença de alunos com deficiência nas equipes para que eles possam, além de auxiliar na criação do conteúdo como os demais, funcionar como consultores, dar dicas e validar a acessibilidade de tudo que for produzido.

O estímulo à produção de conteúdo acessível de modo colaborativo traz como lucro imediato uma maior conexão entre os estudantes. No entanto, essa não é a única vantagem. A longo prazo, atividades como essa ajudam os alunos a se conscientizarem da importância de se construir uma sociedade mais inclusiva, além de lhes garantir a oportunidade de aprender como divulgar suas produções independentes (aquilo que eles usualmente criam e postam sem a interferência da escola) para um público maior.

A escola tem papel importante no letramento digital de seus alunos, quer videntes ou não. É preciso ter o empenho de todos os profissionais, pois não é apenas criar aulas com recursos das tecnologias da informação e comunicação, mas criar um espaço adequado à realização de propostas educativas, tais como: eventos, leituras, discussões, visitas a bibliotecas e museus digitais, dentre outras ações capazes de ampliar o raciocínio crítico dos estudantes e dotá-los de diferentes referências culturais.

Os estudantes precisam estar preparados para atuar em uma sociedade cada vez mais tecnologizada e dominar habilidades que vão desde a capacidade de fazer buscas confiáveis na internet e realizar a leitura crítica dos conteúdos encontrados, até a criação de sítios e canais de vídeo na web que possam ser acessados por todos. Tudo isso de maneira ética e respeitando as diferenças, lutando contra atitudes como o cyberbullying ${ }^{16}$ e a exclusão, sejam elas voltadas ou não a pessoas com deficiência.

\section{Considerações finais}

As TIC podem auxiliar bastante a inclusão de cegos e pessoas com baixa visão no contexto escolar. Apesar da grande carga imagética associada às tecnologias digitais e das barreiras que o seu uso não criterioso pode trazer para esse público, esses educandos têm muito a ganhar com seu emprego em sala de aula. Com o uso de recursos de tecnologia assistiva e dos princípios da $\mathrm{AD}$, associados ao emprego das TIC numa perspectiva que supere o modelo tradicional de transmissão de conhecimentos, videntes

\footnotetext{
${ }^{16}$ Cyberbullying ou assédio virtual é a prática que envolve o uso das TIC para veicular ou dar suporte a imagens e mensagens depreciativas com o intuito de ofender a terceiros.
} 
e pessoas com deficiência visual podem trabalhar de modo colaborativo e construir conhecimentos de modo horizontal, interativo, autônomo e criativo.

A escola é um local de convivência social por excelência, um fórum privilegiado para a discussão de questões como os direitos humanos e o respeito às diferenças. É papel da escola contribuir para que os educandos entendam a importância de se construir uma sociedade mais justa e inclusiva, ao mesmo tempo em que deve ser garantida a esses estudantes a possibilidade de se preparar para atuar numa sociedade cada vez mais tecnologizada.

Esperamos com esse artigo ter contribuído nesse sentido e que professores e estudantes, com deficiência ou não, possam utilizar todo o potencial das TIC para não só tornar a escola, mas também suas comunidades (presenciais ou virtuais), ambientes mais acolhedores e plenos de possibilidades de aprendizado.

\section{Referências}

BOTTENTUIT JUNIOR, J. B.; COUTINHO, C. P. Podcast uma Ferramenta Tecnológica para auxílio ao Ensino de Deficientes Visuais. In: LUSOCOM, 8, 2009, Lisboa. Anais... Lisboa: Universidade Lusófona de Humanidades e Tecnologias, 2009. p. 2114-2126.

BRASIL. Congresso Nacional. LEI No 13.146, DE 6 DE JULHO DE 2015. Lei Brasileira de Inclusão da Pessoa com Deficiência (Estatuto da Pessoa com Deficiência). Brasília, DF, 2015. 42p. Disponível em: <http://www.planalto.gov.br/ccivil_03/_Ato2015-

2018/2015/Lei/L13146.htm>. Acesso em: 26 ago. 2018.

BRASIL. IBGE - Instituto Brasileiro de Geografia e Estatística. Censo demográfico: 2010 características gerais da população, religião e pessoas com deficiência. Disponível em: <http://biblioteca.ibge.gov.br/biblioteca-catalogo?view=detalhes\&id=794>. Acesso em: 6 jul. 2018.

BRASIL. IBGE - Instituto Brasileiro de Geografia e Estatística. Cartilha do Censo 2010 Pessoas com Deficiência. Coordenação-Geral do Sistema de Informações sobre a Pessoa com Deficiência, Brasília: SDH-PR/SNPD, 2012.

KENSKI, V. M. Educação e Tecnologias: o novo ritmo da informação. 8. ed. Campinas, SP: Papirus, 2007.

LEME, M. E. S. A representação da realidade em pessoas cegas desde o nascimento. 2003. 126 f. Dissertação (Mestrado em Educação) - Faculdade de Educação, Universidade Estadual de Campinas, Campinas, 2003. Disponível em: <http://libdigi.unicamp.br>. Acesso em: 30 jul. 2018.

MOSQUERA, C. F. F. Deficiência visual na escola inclusiva. 1. ed. Curitiba: Ibpex, 2010.

MOURA, A. Geração Móvel: um ambiente de aprendizagem suportado por tecnologias móveis para a "Geração Polegar". In: CONFERÊNCIA INTERNACIONAL DE TIC NA 
EDUCAÇÃO, 6, 2009, Braga. Anais... Portugal, Braga: Universidade do Minho: Centro de Competência TIC (CCTIC UM), 2009. p. 49-77.

PILETTI, A. C. da C. Entre os fios e o manto: tecendo a inclusão escolar. 1. ed. São Paulo: Edições Loyola, 2014.

PRETTO, Nelson de Luca; BONILLA, Maria Helena. O Marco Civil da Internet: desafios para a educação. In: EPENN, 22, 2014, Natal, RN. Anais... Natal, RN: ANPEd, 2014. p.1-27.

SILVA, Manoela Cristina C. C. da. Audiodescrição: ferramenta de acessibilidade a serviço da inclusão escolar. In: MIRANDA, T. G.; FILHO, T. A. G. (Orgs). O professor e a educação inclusiva: formação, práticas e lugares. 1. ed. Salvador: EDUFBA, 2012. p. 285-298.

Recebido em: 10 de setembro de 2018.

Aceito em: 07 de dezembro de 2018. 